DOI https://doi.org/10.36059/978-966-397-241-1-3

Hubina O. Yu.

Candidate of Pedagogical Sciences, Associate Professor, Associate Professor at the Foreign Philology and Translation Department Kyiv National Transport University

Kyiv

\title{
INTRODUCTION OF THE BRITISH EXPERIENCE OF USING ONLINE LEARNING INTO THE SYSTEM OF UKRAINIAN EDUCATION IN THE CONDITIONS OF THE CORONAVIRUS PANDEMIC
}

The lack of an appropriate level of readiness of Ukrainian education towards the transition to the principles of openness necessitates the study of this phenomenon. The expediency of scientific study of the conceptual foundations of online learning in Ukrainian universities is due to the need to overcome a number of contradictions in the system of domestic higher education between: modern vector of higher education in Ukraine, aimed at integration into the European Higher Education Area; the growing needs of Ukrainian society in the individualization and technologicalization of education and the insufficient level of methodological support for online learning in domestic higher education institutions.

The scientific problem that has become the subject of study is within the subject fields of such branches of modern pedagogical science as: higher school pedagogy, pedagogical innovation and comparative pedagogy which provides a multifaceted nature of the analysis of its research.

The study clarified the methodological principles of online learning in British universities and outlined the possibilities of its use in the system of domestic higher education.

The characteristic of information and communication technologies used within the framework of online learning in universities has been further developed.

\section{INTRODUCTION}

Relevance and expediency of the study. The development of the information society involves the qualitative modernization of the education sector, especially the introduction of new types of education, including online. 
Of particular importance is online learning in the global education system in the development of the information society with the use of the latest information and communication technologies, distance learning, mastering the relevant skills, abilities and competencies of the individual.

In particular, it was found that the following scientists studied this phenomenon: Allen I., Seaman J., Atkins D., Brown J., Casey G., Evans T., Dalsgaard C., Thestrup K ., Ellsworth J., Ellsworth J., Fullan M., Ganor M., Gaus G., Nichols S., etc.

The purpose of the study is to find out the methodological principles of online learning in British universities.

In accordance with the purpose of the research the tasks are: to identify the state of development of the research problem in the domestic pedagogical science, to characterize the methodological principles of online learning in universities in the UK.

The object of research is online education in British universities.

The subject of research is the methodological principles of online learning in British universities.

Research methods. To achieve this goal, the following methods were used: general scientific (analysis, synthesis, comparison, generalization); specific-scientific (structural-logical analysis, system-functional analysis), empirical (document analysis, electronic correspondence).

The scientific novelty of the obtained results of the research is that for the first time in the Ukrainian pedagogical science the methodical principles of online learning in the universities of Great Britain were clarified. In the context of identifying the state of development of the researched problem, aspects of consideration of online learning are singled out and characterized (theoretical-methodological, educationalpolitical, professional-pedagogical, socio-pedagogical, methodical, technological); conceptual principles (approaches, principles) of the studied educational phenomenon are characterized.

The practical significance of the research results is that the theoretical provisions and factual material obtained during the study can be used in teaching courses on the history of pedagogy, innovative pedagogical technologies, comparative pedagogy of innovative education management. The prognostic potential of the study determines the possibility of using its materials and conclusions for further research 
work on online learning in the process of modernization of the Ukrainian higher education system.

\section{Methodological principles of online learning in British universities}

Next, we describe the innovations in the methodological principles of online learning. We will mainly focus on the structuring of the curriculum, its integration into a single educational and information space, design and implementation of innovative e-learning technologies, the creation of teaching materials focused on use in the online learning system.

Note that the progressive experience of using innovative methods and technologies that will be the subject of our consideration can be used in the traditional system of education (full-time, mixed), but researchers rightly insist on the special relevance of the following methodological and technological innovations for use in on-online learning.

Analysis and generalization of a wide range of sources (analytical reports of experts from national and supranational organizations, university documents, scientific research of individual experts and research teams) allows us to state that the initiators of the most successful strategic programs for innovative methods and IT technologies in the modern system of open learning are: Universities of the country (Open University, Greenwich, Leeds, Cardiff, Strathclyde, Ulster, City University, Brunel University, University of the South Bank of London, University of Cambridge and the University of Reading), organization "Learning Management System" (also Lam International Ltd) and the Committee of Unified Information Systems (JISC) and the Academy of Higher Education [11].

In the context of our study special attention should be paid to the program "Transformation of educational services through technology", developed by a number of universities, namely: the Universities of Open and London, Oxford, Coventry, Newcastle, Bristol and Leicester, on the base of which numerous projects were tasted [11].

Next, based on the generalization and systematization of materials of the above projects, we will find out the most successful methodological principles among them. The whole set of analyzed projects is divided into two groups: 1) projects related to innovations in the methodology of any 
subject areas in the open learning system; 2) projects related to innovations in the methodology of teaching certain subject areas.

First of all, let's pay attention to those projects that are of general character and relate to any subject area in terms of providing online learning.

The project "Development of new models to support lifelong learning at Oxford University" aims to develop tools, systems and resources that allow teachers and administrative staff to work successfully in a virtual learning environment within any training course. The aim of the project is to address the following issues: online task management, support for courses in a virtual learning environment, design of general content and course design [4].

The problem of solving of online task management aims to technically adapt the new program for processing tasks based on Moodle: reducing the time of early expansion of the module (both the creation of a new module and modification of existing ones); control of the working process of the register (reflect the process of ensuring the quality of tasks); Moodle enhancements Add mandatory additional input parameters (for example, automatic word count and anti-plagiarism program) in the "task submission" item. Successful implementation of this issue simplifies and makes more accessible and flexible the process of submitting completed tasks to students, as well as ensures time efficiency in the process of task processing, control and audit for teachers, registry staff and IT support staff.

The developers point out that the goal of supporting courses in the virtual learning environment is not only to create a set of templates in the Moodle system, each of which includes certain administrative and academic content relevant to a particular course, but also recommendations and tools to help virtual learning users, as well as developing an administrative interface to create a new course. The purpose of the general content design program is to identify sources of information that can be used in a virtual learning environment, and the best format and methods of presentation of this material [4].

Sources of information that can be freely used by educational entities include: library repository, induction materials, general background information on the curriculum, citations and references, student 
reference books, feedback forms, manuals on tools and software. The course design is designed on the Phoebe platform [4].

The Coventry Online Academic Writing Lab project aims to address the need to support students in academic writing. The site where the online lab is located is part of the Academic Writing Center website. Access to website support services is open. This application is based on the Moodle platform, which allows students to participate in online classes, download assignments, connect to online sessions and have the opportunity to feedback to tutors in extracurricular time. In online classes, tutors not only provide knowledge to students, but also help them evaluate their own writing, provide advice on certain types of tasks, and students have open access to a wide range of resources that contain recommendations, rules and examples of correct writing. Learning tools include online conferences with Web 2.0 technology, which provides synchronous communication with the tutor, voice instruments, including SpeakingFox, SpokenText, Text to Voice, text2speech and more. Students can study online both in groups and individually [2].

The results of the project were implemented on the basis of the University of Nottingham and the University of London College.

The Dynamic Curriculum project developed and evaluated navigational dynamic curricula that combine Semantic Network and Web 2.0 approaches based on technologies and standards to combine resources and learning information (managed learning environments) and personal training records (e-portfolio, blogs).

The project aims to improve the understanding and navigation of the curriculum and provide students with the means to develop actively their own curriculum, contextualization, reflection and study. Within the educational process, the teaching staff cooperates with the student community, which includes the exchange of information, evaluation and discussion of issues related to the curriculum. The dynamism of the plans is characterized by cross-module connections, as subjects are studied in more depth with each passing school year. Students can use current plans to determine previous and future study plans to avoid duplication of subjects, and have the opportunity to fill gaps in their learning by reviewing the course plan. By studying a particular subject, users not only receive links to useful materials on the Internet related to training 
sessions, but also can leave their own links to found sources, resulting in a rating of "best resources". Students upload to the e-portfolio their essays, notes, personal comments on educational materials that they can share in the chat. Teachers also have the opportunity to use dynamic curricula. In preparing for lectures, they can use students' links to useful sources, use information from parallel disciplines, read student annotations that give the teacher an understanding of their mastery of the subject and take into account their wishes [5].

The results of the project were tested at the universities of Greenwich, Surrey and Wolverhanton.

The project "Presentation of University Curricula: Knowledge, Learning and Innovation" demonstrates a practical combination of approaches to the introduction of new technologies to develop learning, communication and assessment skills. Learning within this project takes place using four technologies: podcast, Second Life, e-book readers and Wimba Voice Board, which increases not only the quality of learning but interactivity and flexibility of educational programs. The program uses the following tools and technologies:

1. Podcasts, which are episodic series of digital audio or video files that students can download and listen to on computers, mobile applications, or portable media players. Podcasts are distributed through the Blackboard University web channel. The use of podcast technology contributes to the enrichment of teaching approaches to teaching. Listen to podcasts via mp3, mp4 players and AAC files. The main characteristics of podcasts are their portability and mobility.

2. Second Life is a virtual 3D environment where students can build their knowledge through images, voices and synchronous / asynchronous interactive exercises. The use of Second Life technology will improve the interactive work between teachers and students, especially thanks to the Blackboard web bulletin board. Also, with the possibility of asynchronous communication, the student can perform tasks at a convenient time and place. Second Life enables virtual face-to-face meetings, conversational or text chat, simulation of real scenarios, etc.

3. E-book reader - a portable device for reading e-books. Specialized devices include smartphones, tablets, iPads, and computers with related software. The device sends students handouts, as well as spreadsheets, 
movie files, programs, audio and other PowerPoint files in one portable, readable package. The advantages of this technology are its flexibility and mobility - the study material can be studied in a convenient place and time.

4. Wimba Voice Board is a set of web-based tools that provide synchronous and asynchronous voice work, such as audio discussions, conferences, lectures, podcasts, instructions, online voice presentations, and more. Learning is more emotional and interesting, and therefore its advantages are a sense of "real" and "personal", which brings students together, bringing learning closer to the classroom, while enabling distance learning [3].

The introduction of a number of universities mentioned above in the educational process allowed the authors to confirm that the advantages of using innovative technologies are: increasing flexibility and mobility of learning, reducing student isolation by providing additional opportunities for teachers and students to participate in learning, intensifying innovative learning skills [3].

The aim of the Feedback project is to improve the feedback between the student and the teacher in the framework of learning programs by developing an innovative technological system. Electronic technologies available in the virtual learning environment are used to develop an integrated process that compares feedback with the reflection of students' opinions, which helps to increase learning productivity and inform about their success. The use of feedback technology provides the teaching staff with a centralized transparent system that improves the overall management of students' learning practices. The project at the University of Westminster uses the "Electronic Feedback" model, which is a threestage process of feedback from teachers to students during the evaluation of student work:

I stage - the student receives the work checked by the teacher where not only an estimation, but also the provided comments and remarks are specified;

Stage II - the student fills out an electronic questionnaire, which expresses his views on the evaluation of his work, answering questions about their own expected results, time spent on work, actions after receiving the results (consultation with the teacher, understanding of 
their mistakes, etc.). Questionnaire responses are processed and automatically sent to the student with advice on their answers, such as planning and completing the task, evaluation criteria, teachers; they can turn to for help, and so on.

Stage III - in the e-journal, the student presents the report data in his / her own feedback blog and discusses it with his / her tutor online or during a meeting [9].

The goal of the Technology Integration project is to increase the effectiveness of teaching and learning through the use of modern ICT, which makes the process of acquiring knowledge more flexible and accessible. In this project, the following technologies are used during the educational process at the university:

1. Flip video. Use of portable video recorders for filming presentations, experiments, lectures, and other educational activities. Students upload these videos to the university's website or Facebook, exchange views, and the best of the videos can be used in student projects or research.

2. SMS. Use mobile technology to provide feedback to students. Using their own phones, students send text answers to the PAYG number. Sent messages are processed in Excel and then a graphical representation of the results is compiled, or sent to Wordle clouds to create a visual presentation. It is also possible to use other technologies, such as: MS Excel, Nokia PC Suite, Bluetooth, cloud technologies. The results of student work can also be discussed in lectures and practical classes.

3. Audience Response System. The use of special mobile devices, most often smartphones, allows students to feedback from teachers and increase their participation in the learning process. This technology is possible for small groups and is built in such a way that in case of difficulties with the assimilation of information, students send a message to the teacher, who, taking into account this information further clarifies the material. There are various interactive learning scenarios where this technology can be used, such as: event management (by voting in the classroom, students can directly signal which approach should be used to present material or solve certain problems within the current course, thus contributing to event management), speed control (students evaluate the speed of the lecture, taking into account the message, the lecturer can 
change the pace of teaching material), display content (students report difficulties in learning the material, and the teacher explains the incomprehensible).

4. Echo360, which is a training platform with cloud service. The platform centrally stores lectures and hyperlinks to sources of information that the student can view at any time. Online, students can take notes, ask questions about recorded lectures, and copy and save parts or the full version of presentations, slides, or lectures.

5. Screenshot. The use of this technology is possible with the use of a tablet PC. Thanks to the Screenshot, students have the opportunity to take screenshots with explanations of the material during classes. Screenshots can be accessed through the WebCT system.

6. Computer-Aided Assessment. Automated computer-based assessment covers all forms of assessment: summative (tests that help assess formal qualifications) or formative (tests that help assess and improve the learning process) and is done with the help of computers. One of the most common forms of computer-based assessment in the open learning system is online quizzes or exams.

7. E-portfolio. Individual student profile, which stores electronic files with personal information, learning outcomes, images, multimedia, blog entries, hyperlinks [8].

The project was implemented on the basis of the University of Exter.

The aim of the project "Television Studio on the Internet" is to provide students with the opportunity to gain real experience in the field of fullfeatured television production. Among the tasks of the project are the following:

- $\quad$ to create an Internet TV channel that works mainly with students of the Faculty of Media Arts under the guidance of experienced media professionals;

- $\quad$ to improve curricula by providing innovative learning experiences during which students can develop modern media skills in "real" television production and broadcasting;

- to combine the work of the channel with learning through the network "Learning Net" on the basis of an improved virtual learning environment of the college;

- $\quad$ to involve media students in practical work in media production. 
Implementation of the project tasks will contribute to: improvement of curricula that will ensure the implementation of media production, involvement of staff in creating basic skills of innovative learning resources, creating curricula that will meet the needs of students, improving the skills of media students.

Accordingly, the College of West England has created a television channel and online TV center "Springboard TV", which employs specialized media professionals and a group of media students. The channel is designed to provide college students with opportunities to demonstrate their skills and academic research results, combining their coursework with hands-on work in media, film and television. The educational process is as follows:

1. Reproduces a "realistic" production environment.

2. A professional from the media environment (producer, director, etc.) works with each group within the framework of practical classes.

3. Practical groups consist of students from different courses to better share experiences, provide support and assistance. For example, more experienced third-year students can take on complex roles (director, producer, writer, editor, etc.), and less experienced 2nd year gets less complex roles (sound engineer, cinematographer).

4. Blogging, which gives students the opportunity to share ideas, and teachers - understanding the success of student learning [10].

Senior students have a mandatory internship to create a video product on their own at the request of external organizations or departments of the college. The student is assisted by a team consisting of a producer, cameraman, sound engineer, etc.

To improve teaching on the basis of the college, Golden Hour seminars were organized, where teachers gained experience in the field of digital technology, which further simplified the online assessment procedure, which allows students to submit written work in electronic form, get grades with feedback in a similar format, and monitor learning performance.

On the basis of this studio there are 15 channels, including: "Real Time", "History", "Sports", "Comedy", "Experimental", "News", "Awards", "Eurochannel", "Movies", "Music" "Art", "Documentary", "Demonstration of student work", "Former student", (demonstration of modern work of 
former students) and "Extended channel". The creation of a television studio on the basis of the college contributes to the improvement of teaching and learning skills for both teachers and students of the Faculty of Media Arts.

After researching the methodological principles of each project, we concluded that the overall goal of the program "Transformational provision of educational services through technology" is the ability to build innovative curriculum design and its effective implementation through appropriate technical means. Innovative design includes: providing advice and recommendations, providing feedback, evaluation, building programs of individual and joint (group) learning, in developing skills and practices of access to curriculum resources. The program aims to support lifelong learning and provides curricula that meet the changing needs of students for flexible access to learning through the use of innovative technologies. Technologies used include virtual learning environments (VLEs), content management systems, development learning tools, assessment technologies, media, advanced learning technologies, social networking and Web 2.0 technologies, mobile technologies, e-portfolios, and semantic web technologies.

The implementation of the program objectives for the construction and implementation of curricula in the process of acquiring knowledge through ICT is subject to certain requirements for the organization of the educational process and the use of technological tools that meet the logic of open education [11].

I. The organization of the innovative educational process takes into account three components:

- organizational work (expanding participation and diversification of student representation, providing student access to education, career guidance among students, meeting employment requirements, improving the efficiency of business processes and organizational efficiency);

- flexible curriculum (development and presentation of open and accessible program);

- Student-centered learning (student-centered improvement of skills in authentic situations, interaction of learning communities, feedback and assessment. 
II. The technological means of virtual learning environment in the open education system include the following:

- storage technologies (the ability to create, store and use information within open educational resources);

- tools of educational design (creation by establishments of own interactive educational tools);

- evaluation technologies (ability to establish feedback and use various evaluation mechanisms);

- media (use of multimedia tools for online lectures, webinars, presentations, etc.);

- mobile technologies (use of mobile phones, SMS messages, tablet PCs, ultraportable laptops, netbooks, e-books, iPods, etc.);

- e-portfolios (the ability to plan, collect, share information through portfolio tools and systems that help students portray evidence of their achievements and support the employment program; e-portfolios help support personal development planning, continuing professional development, assessment and feedback);

- $\quad$ social networks and web technologies (opportunity to develop academic training, encourage and support open and public practice, interaction directly with employers through digital technologies in both formal and non-formal learning);

Thus, having studied the goals and objectives of this program, we can outline its advantages, which are in the technological and methodological areas.

Advantages of the program "Transformational provision of educational services through technology" in technological and methodological areas

Technological plane:

1. Technology is able to support more accessible and flexible methodological approaches to teaching and learning, collaboration, and creativity.

2. The wide range of ICT available to students provides opportunities to improve methodological approaches to learning, as well as use in formal or non-formal learning contexts.

3. Integrated information systems support the development of institutional training programs. 
4. The use of technology allows to simplify organizational issues: saving time for students and teachers, improving the management of the educational process, research into the effectiveness of technology, providing online support for the learning process.

Methodical plane

1. The curriculum meets the needs of stakeholders, is flexible and open to change, retains the specifics of the specialty.

2. The training program meets the professional requirements of employers.

3. Innovative methodology provides students with opportunities to:

a) create your own content that meets individual educational needs;

b) create an e-portfolio that provides an opportunity to better demonstrate the student's competence and appropriate assessment;

c) it is methodologically justified to use digital media, which promotes constant dialogue, for example, employers with representatives of institutions, and ensures the process of mutual continuous information.

Next, we describe several methodological and technological innovations used in some subject areas, such as design, medicine, biology. Note that the following techniques and technologies can be used in traditional full-time education systems, but in the system of open education, they are especially relevant.

The project "Achieving the Transformation of Advanced Learning and Innovation through the Introduction of Educational Resources in Design Education" provides the use of virtual studio techniques, which combines well-established practices in art and design education with new opportunities through ICT in teaching and learning design. The project is presented on the OpenLearn platform at the initiative of the Open University, using Web 2.0 tools (such as video conferencing and social networking applications), knowledge creation software and a virtual design studio. The Virtual Design Studio is an image-sharing interface that allows design students to upload their own projects, share ideas, comment on other students' work, and consult with course instructors. To this end, the user creates his profile - a portfolio of personal information, their own design projects, and the page displays the current assessment of the student's performance. The virtual studio supports distance learning students in creating a virtual network of designers who exhibit their work 
on the Internet. To improve learning within this project, participants in the educational process have the opportunity to use a special website of the social network Ning as a platform for communication and learning within the design program. The aim is to support the interaction of students and teachers in the organization of creative events, exhibitions and forums, which plays a positive role in the development of design culture. The Ning network provides asynchronous and synchronous communication of topic groups through online chats and discussion forums, as well as the exchange of photos, videos and provides functionality such as tagging, commenting and rating. Ning has two main functions: first, the network's website serves as a repository of design information and ideas, constantly updated with design news, design ideas, and interesting design work by students, faculty, or the course team using videos or photographs. Secondly, the website also plays the role of a space where synchronous or asynchronous discussions with students and teachers take place [1]. The partners of the project are: the Universities of Leicester, Oxford, London and Birmingham City.

The implementation of the Generation 4 project involves the use of innovative methods to create an interactive and integrated educational model for teaching in the field of medicine. This is primarily the use of interactive computer modeling of the real state of the virtual patient and the reproduction of clinical scenarios. The aim of the project is to create a more adaptive, personalized approach to learning, aimed at forming professional competence, which more accurately corresponds to the specifics of a particular specialty (practitioner). The task of the project is to develop interactive technologies to recreate situations where students are given the opportunity to treat the patient and explore the consequences of their actions. To achieve the goals of the project, the university management provides for the creation of 18 interactive virtual patients, 36 scenarios of their disease using Web 2.0 tools.

Specialists in professional disciplines and IR technologies adapt scenarios to create interactive, integrated, adaptive cases using existing technologies. Each case is integrated with a variety of Web 2.0 resources, ratings, e-portfolios and tools. through the OpenLabyrinth Virtual Patient system. Thanks to the open education system at the university, you can obtain a bachelor's, master's or doctoral degree in biomedicine or health 
care, as well as a physiotherapist, paramedic, nurse, obstetrician, doctor of diagnostic or therapeutic radiography. As part of the project, the university is collaborating with the universities of Newcastle and Coventry.

The project "E-Biolaboratories: a personalized virtual environment to support laboratory learning of biology" aims to transform laboratory courses into more active and open through tools that allow students to interact and contextualize tasks in a 3-dimensional virtual environment. In E-Biolaboratories, which contain high-quality online materials, practical classes take place in three stages:

- acquaintance with experimental information;

- $\quad$ performing the task before the start of laboratory work;

- passing tests after experiments.

At the first stage, students get acquainted with the experimental base (methods and techniques of research, equipment), which with the help of high quality tools (interactive animations and videos) facilitates the work of students in the process of data transfer and calculations.

At the second stage the degree of assimilation of experimental information by the student is checked. There are two attempts to complete the test tasks of the quiz, after which the average score is set, which is $20-30 \%$ of the total score. Tasks are checked automatically and the results are immediately posted on the Internet.

At the third stage - after the experiment, students enter their data from their laboratory book into the electronic form of the E-Biolaboratory. If the answer to the problem has an algorithmic solution, it is automatically indicated in the E-Biolaboratory. After receiving the results, students have the opportunity to analyze their work through Excel Visual Basic. Checking student performance is simplified by using the e-application "Evaluation, visits and feedback" [6].

The project was implemented at the universities of Bristol, Manchester, Nottingham and Cambridge.

Thus, universities that use open and distance learning methods, such as Oxford, Cambridge, University of London and Open University, etc., take into account the institution's strategy for open and flexible learning and the specifics of specific subject areas. Curricula are properly designed to 
best meet the needs of students in affordable and quality education, after which the student receives a certificate, diploma or academic degree.

Thus, online learning combines innovative ICT-based teaching methods and tools to improve the quality of teaching in UK universities.

\section{The opportunities to use the progressive experience of the United Kingdom in the development of online learning in the universities of modern Ukraine}

The current trend of organizational transformations in Ukraine in the field of online learning is the creation of national information and communication infrastructure through a number of measures: creation of government agencies and structures for the organization and implementation of open education, ICT. In the UK, it is time to further improve the system of open learning by further diversifying a wide range of educational services, implementing innovative projects, establishing close cooperation between enterprises and enterprises, implementing a student-centered approach to learning.

An analysis of methodological and technological principles of online learning in the universities of Great Britain shows that the most important features of system are: introduction of technological equipment taking into account the specifics of a particular subject and specialty; development and implementation of methods of student-centered learning; development of criteria and technologies for ensuring high quality online education; providing opportunities for continuous professional development of teachers working within the framework of open education programs.

The main task of distance learning is to provide citizens with the opportunity to exercise the constitutional right to education and professional qualifications, training regardless of gender, race, nationality, social and property status, gender and nature of occupation, worldview, party affiliation, religion, religion, state of health, place of residence according to their abilities.

A successful step in implementing the tasks of the government regarding the organization of online learning is the effective modernization of the content and organizational structure of higher education. An integral part of online learning is open learning, which is implemented through the distance learning system as part of the 
education system of the country, with the legal framework, organizational structure, personnel, technical, logistical and financial support, which implements open learning levels of higher, postgraduate, lifelong learning, and self-education. Following the President's order on the "Regulations on Distance Learning", distance learning centers began to be organized on the basis of universities, which needed clear coordination.

A number of state institutions and organizations, in particular the Department of Higher Education of the Ministry of Education and Science of Ukraine, deal with the organization and implementation of open education in Ukraine; Ukrainian Institute of Information Technologies and Teaching Aids (NAPP); Institute for Modernization of Educational Content; Institute of Educational Analytics, Ministry of Education and Science; Coordination Council for the Development of Distance Learning at the Ministry of Education and Science of Ukraine; commission at the Coordinating Council in certain areas of ensuring the development of the distance learning system, the main, regional, basic and local centers of the distance learning system, which perform certain functions

Given the urgency to the problem of innovative development of online learning in universities, it is advisable to use the progressive British experience in Ukraine at the state, local and institutional levels, in the following aspects: legislative, educational, political, organizational and pedagogical, scientific and methodological, technological.

State level.

Regulatory and legal aspect.

Further development of the legal framework in the field of online learning, in our opinion, involves:

1. Inclusion of the section on organizational principles of development of open education in the Law "On Higher Education".

2. Development of a comprehensive "Open Education Development Program in Ukraine", the main task of which will be to promote open education in the domestic market of educational services.

3. Development of the Cabinet of Ministers of Ukraine Regulations "On organizational, scientific, methodological and financial support of the process of implementing open education in the Free Economic Zone". 
4. Development of the state program "On training and retraining of teachers to work in the information and communication environment" taking into account European standards of ICT competence of teachers.

Educational and political aspect.

1. Further development of cooperation between educational and political, scientific, academic, ICT communities, public organizations in the implementation of open education; dissemination of the practice of bringing useful information on the progressive world and national experience of open education to all stakeholders through scientific and methodological activities in the form of forums, seminars; placing in free access publications in the media and the Internet on the results of the introduction of innovations in the educational process: reports on the effectiveness of training, teaching, research and financial support of universities in the country.

2. We consider it important to develop mechanisms for differentiated government financial support for universities for the most effective innovation activities in the form of investing in innovation programs, providing grants for digital disciplines based on national colleges or universities, funding research projects, programs to improve the quality of education. ICT and further assistance in employment of graduates of computer science faculties.

We consider it useful to introduce similar practices in Ukraine and develop mechanisms for financial support of universities with more proactive innovative activities in the field of online learning.

Organizational and pedagogical aspect.

1. A significant achievement in the development of online learning is the holding of relevant open scientific conferences, lectures, seminars, etc. by British universities. This is a good opportunity for both professionals and students to acquire relevant knowledge and exchange useful information on the organization of the educational process, development of educational and methodological programs and more.

We consider it important to organize and conduct similar scientific and practical events in the form of open face-to-face or online lectures, seminars with the participation of leading Ukrainian higher education institutions on the basis of relevant institutions (centers) of open education. This will contribute not only to the promotion of open 
education, but also the opportunity to acquire certain knowledge and competencies in this field.

2. An important component of the UK education sector is research institutions that promote national and local innovation systems, such as: providing access to research objects, unique data sets and collections; providing scientific advice on the development of public policy on educational innovation.

We believe that supporting this practice of providing knowledge and data on innovative educational systems and their relationship with industrial enterprises in Ukraine will improve the country's industry by taking into account the performance of these research institutions.

3. We consider it expedient to organize international cooperation between British and domestic universities of open education for the exchange of knowledge and experience of open learning. To this end, we consider it necessary to conclude agreements both at the educationalpolitical (between government structures) and at the institutional (between universities) levels, to include Ukrainian scientists, administrators and teachers in the activities of professional networks of the relevant profile.

4. It is necessary to spread and intensify the training of teachers to work in the open education system. To this end, it is necessary to organize training centers on computer technology, which will host lectures, individual lessons, round tables, training in computer technology, practical work in the halls of electronic resources, remote modules, etc. Upon completion of the courses, a certificate of the appropriate level will be issued:

I - technical literacy;

II - in-depth knowledge;

III - the creation of new knowledge.

Scientific and methodological aspect.

We consider the creation of a national methodological center for the dissemination of open education to be an important step in improving the effectiveness of open education development management in Ukraine. The actions of this organization should be aimed at defining a strategy for the development of open education and its implementation in higher education (basic education, second higher education, retraining and 
advanced training), providing recommendations on hybrid and open universities, developing methods of training and retraining, providing educational and methodological materials to the subjects of the educational process, material and technical support of scientists researching this problem, conducting methodological activities in the form of forums and seminars, developing framework standards for the educational process in open universities and dissemination of innovations.

Regional level.

Scientific and methodological aspect.

We consider it useful to organize regional methodological centers, whose responsibilities will include providing useful information on new tools and methods of teaching in the open education system. Conducting master classes and practical classes, where representatives of the educational community will have the opportunity not only to get acquainted with innovations in teaching, but also to share experiences and ideas.

Organizational and pedagogical aspect.

We consider it necessary to organize regional centers for coordination of open education development in order to ensure its effective implementation within the Higher Institutions in the respective regions. We consider it a good practice to hold conferences, seminars and scientific events during the year to discuss and further implement key issues of regional education policy.

A necessary condition for the development of higher education is the creation of local centers for training / retraining of teachers to work in the information and communication environment: providing consulting support to specialists, learning to work with ICT, open educational resources, learning about advanced teaching methods in innovative learning environments.

Institutional level.

Educational and political aspect.

UK universities support effective collaboration with industry sectors, businesses, industry to develop, implement research projects to improve training and further employment. To this end, open forums and online seminars are organized, and information is freely available on the 
conditions and proposals for cooperation of higher education institutions with industry sectors and enterprises. Higher education meets the needs of modern society and each individual. The cooperation of universities with local employment services in terms of providing information, advice and recommendations on employment and training of students (especially on further education, apprenticeship) is active and effective.

We consider it expedient to introduce in modern higher education in Ukraine a practice aimed at intensifying the cooperation of the Higher Institutions with local employment services to provide employment opportunities after graduation or further vocational education.

In our opinion, the implementation of the following aspects of activity will be important:

- interaction of universities not only with domestic, but also with foreign enterprises, scientific organizations. It will be useful to hold open events to provide stakeholders with information on open education and further employment opportunities. Such a policy will contribute not only to the innovative activity of the population of Ukraine, but also to the effective interaction of universities with enterprises and industry sectors of science in order to improve the training of specialists with possible further employment of graduates;

- participation of universities in the creation and development of domestic (regional) innovation clusters.

Organizational and pedagogical aspect.

1. It is important for open British universities to focus on innovation and science through the desire to: create high-quality open learning; bring together communities of practitioners and teams of innovative scientists working on teaching and learning issues; provide financial support to communities of practitioners for scientific achievements; create an innovative "engine" in the existing scientific platform; to support the program of continuous professional development of staff and their work in the field of science and innovation; provide opportunities for remote cooperation between universities to share cutting-edge achievements.

Therefore, in our opinion, we consider it necessary to provide existing domestic universities with greater autonomy, which will help improve the overall learning strategy that will clearly meet the needs and requirements of students and teachers: the ability to choose students of 
certain courses, providing support to graduates in employment through joint, coordinated activities of enterprises and universities.

2. Effective implementation of open learning is ensured by the improved ability of teachers to work in the information and communication environment. Given these requirements, we consider it necessary to organize appropriate courses with practical classes, individual coaching sessions and consultations on training and retraining of participants in the learning process to work in this environment. Upon completion of training, course attendees, depending on their qualifications (teacher, laboratory assistant, librarian, etc.) must be issued certificates in accordance with European standards of ICT competence of teachers:

I level - general technical literacy of teachers, necessary for providing students with comprehensive training with the possibility of their adaptation to specific tasks; practical knowledge of Office products; basic technological knowledge of computer science and ICT infrastructure;

Level II - deepening knowledge - ICT literacy to manage information, create and monitor individual and group student projects, increase the availability of information and experts, support the cooperation of teachers to support their own professional learning;

Level III - creating new knowledge - the ability to use ICT to create innovative programs (through which students will acquire skills such as problem solving, collaboration, experimentation, critical thinking, creative experiment), conducting educational experiments using various network devices, digital resources, electronic environments.

ICT literacy of teaching staff will contribute to the development of readiness to create strategic plans and programs, the successful implementation of which contributes to improving the educational process, namely: supporting current student learning, creating a favorable personalized learning environment, active participation of participants in research projects and research, access to open educational resources.

In our opinion, it will be useful to learn English while attending computer courses, as a lot of information on the Internet is in English.

3. It is worth noting the activities of research laboratories established on the basis of British universities, aimed at technological support of flexible, adaptive curricula, introduction of new teaching methods, 
improvement of personalized curriculum, development of new models of presentation and support of lifelong learning and more.

In our opinion, the creation of similar laboratories on the basis of domestic universities will provide an opportunity to improve the quality of teaching and learning in the context of systematic informatization of education.

Technological aspect.

The successful implementation of the open learning process in British universities is due to the use of modern information and communication technologies that make it accessible and flexible. With the help of the Internet and computer technology it is possible to organize distance learning, diversify teaching methods (individual, group), forms of learning (online lectures, seminars, forums, projects), provide access to open educational resources.

We consider it necessary to improve the material and technical base of Ukrainian universities: providing higher education institutions with the necessary computer equipment - modern innovative gadgets, creating an IR environment - e-libraries, electronic databases, distance learning courses, providing free access to open educational resources.

The use of modern technological equipment by universities will allow to expand the opportunities of institutions in providing quality and affordable education to those who wish. This is not only an opportunity to study remotely and get free access to educational content, but also to diversify the educational process through innovative multimedia tools.

Thus, summarizing the experience of open universities, the UK offers the following steps to improve the development of open education in Ukrainian universities:

1. Development of the "Strategy for the Development of Open Education in Ukraine", which will promote and promote open education in the domestic market of educational services, as well as expand the interaction of domestic higher education institutions with foreign ones in the field of open education.

2. Establishment of methodological centers of open education, whose responsibilities will include: providing recommendations on the activities of universities of open education, development of methods for training and retraining of teachers, providing teaching materials to the subjects of 
the educational process, technical support for researchers problem, implementation of methodological measures, development and improvement of framework standards of the educational process in open universities and dissemination of innovations that will facilitate the rapid implementation of open learning.

3. Reorganization of traditional universities into open or hybrid universities, accelerating the process of opening distance learning offices in order to promote lifelong learning and provide opportunities for all comers.

4. Intensive introduction of IR technologies and tools in the educational process, including quality work of Internet providers, network and telecommunication equipment, computer systems, educational equipment, screen and audio teaching aids, software and methodological complexes, etc.

5. Inclusion of the tasks of acquiring ICT skills in the mandatory program of professional development of Higher Institutions teachers

Thus, the introduction of principles, methods, forms and means of open learning in the higher education system will provide opportunities to accelerate the development of important areas of modern Ukrainian society and facilitate the country's adaptation to the world scientific and educational space. The use of the British experience of open education will contribute to the modernization of Ukraine's higher education system in the context of modern innovative development of society.

\section{Conclusions}

The methodological structure of the researched educational phenomenon is outlined in the work. Analysis of the methodological foundations of online learning in British universities revealed that the innovative search of the academic community is focused in this area on structuring the curriculum, its integration into a single educational and information space, design and implementation of innovative e-learning technologies, creating new educational methodological materials focused on the use of open education, which are both general and specialized, taking into account the specifics of individual fields of knowledge, their sections and thematic areas (innovative program "Transformational provision of educational services through technology"). 
It was found that the trends of further development of methodological principles of online learning in British universities are as follows: improving the methodology of open education in the implementation of national strategies for access to education; development of a new methodology for designing learning through innovative approaches to the development of educational programs; updating IT technologies for distance learning; development and implementation of innovative methods of using ICT in the educational process; improving the system of continuing professional education of teachers.

Thus, clarifying the methodological principles of online learning in British universities allowed us to state that the main directions of development of online learning as a social phenomenon are democratization, diversification and massification of educational services; as an educational phenomenon - individualization, intensification, internationalization, informatization of the process of acquiring knowledge and professional qualifications.

Based on the elucidation of organizational and pedagogical principles of online learning in British universities, recommendations for the use of elements of progressive British experience in terms of the research problem in Ukraine at the national, regional and institutional levels in educational, political, organizational, pedagogical, scientific and methodological and technological aspects. Among the submitted recommendations, the most promising for implementation at the present stage are singled out.

At the national level, it is advisable to improve and detail the normative provision of online learning. We consider it necessary to further develop the practice of creating open universities, the Center for Open Education Development, which should be the coordination center between higher education institutions, the National Academy of Sciences of Ukraine, the National Academy of Pedagogical Sciences of Ukraine, MES of Ukraine. It is important to improve the mechanisms of differentiated government financial support for higher education institutions in innovative activities to improve the methods and technologies of open education.

At the regional level, it is important to create regional centers for training / retraining of teachers to work in the information and communication environment: learning to work with ICT, open 
educational resources, learning about advanced teaching methods in innovative learning environments, providing consulting support and more.

At the institutional level, it is important to establish effective cooperation with industry research institutions, enterprises, ICT developers. It is necessary to properly provide the educational process with innovative multimedia tools, as well as quality work of Internet providers. Particular attention is paid to the organization of scientific and methodological work of universities within the framework of open education: creating an open learning environment, supporting programs of continuous professional development of staff and their work in the field of science and innovation; providing opportunities for networking between universities to share progressive experiences.

Thus, a comparative analysis of the methodological foundations of online learning in British and domestic universities allowed to justify the use of elements of progressive British experience in terms of the problem in Ukraine at the national, local and institutional levels in educational, political, organizational and pedagogical, scientific, methodological and technological aspects.

\section{References}

1. Achieving Transformation, Enhanced Learning and Innovation through Educational Resources in Design. Open University project. URL: http://webarchive.nationalarchives.gov.uk/20140702144948/http:// www.jisc.ac.uk/whatwedo/programmes/elearning/curriculumdelivery/ atelierd.Aspx

2. COWL Final Report. URL: http:// webarchive.nationalarchives.gov.uk/ 20140702150031/http://www.jisc.ac.uk/whatwedo/programmes/elearnin g/curriculumdelivery/cowl.aspx.

3. Delivering University Curricula: Knowledge, Learning and INnovation Gains (DUCKLING). SMEL project University of Leicester. URL: http://www2.le.ac.uk/departments/beyond-distance-researchalliance/projects/duckling?uol_r=f5d83a92

4. Developing new models to transform the delivery and support of learning for continuing and professional learners at the University of Oxford.

Oxford

University

project.

URL:

http:// 
webarchive.nationalarchives.gov.uk/20140702145449/http:// www.jisc.ac.uk/whatwedo/programmes/elearning/curriculumdelivery/ cascade.aspx

5. Dynamic Learning Maps. Final report of Newcastle University. URL: http://webarchive.nationalarchives.gov.uk/20140702150551/ http://www.jisc.ac.uk/whatwedo/programmes/elearning/curriculumde livery/dynamiclearningmaps.Aspx

6. eBioLabs: A personalised virtual environment to support laboratory-based bioscience. Final report of Bristol university. URL: http://webarchive.nationalarchives.gov.uk/20140702150615/http:// www.jisc.ac.uk/whatwedo/programmes/elearning/curriculumdelivery/ ebiolabs.aspx

7. G4 Final Report St George's University of London. URL: http://webarchive.nationalarchives.gov.uk/20140702195932/http:// www.jisc.ac.uk/whatwedo/programmes/elearning/curriculumdelivery/ fundedprojects.aspx

8. Integrative Technologies Project. URL: https://projects.exeter.ac.uk/ integrate/

9. Making Assessment Count. URL: http://sites.google.com/a/ staff.westminster. ac.uk /mac/Home/expected-outcomes

10. SpringboardTV: An internet TV station to enrich teaching \& learning. College of West Anglia report. URL: http://webarchive.nationalarchives.gov.uk/20140702153858/http:// www.jisc.ac.uk/whatwedo/programmes/elearning/curriculumdelivery/ kltv.aspx

11. Transforming Curriculum Delivery through Technology. Programme Synthesis Report Curriculum innovation: pragmatic. URL: http://http://webarchive.nationalarchives.gov.uk/20140702233839/ht tp://www.jisc.ac.uk/whatwedo/programmes/elearning/curriculumdeli very/fundedprojects.aspx 